\title{
PHILIPPE BERTHIER, Chateaubriand chemin faisant
}

\section{Sébastien Baudoin}

\section{OpenEdition}

\section{Journals}

Édition électronique

URL : https://journals.openedition.org/studifrancesi/11826

DOI : 10.4000/studifrancesi. 11826

ISSN : 2421-5856

\section{Éditeur}

Rosenberg \& Sellier

\section{Édition imprimée}

Date de publication : 1 avril 2018

Pagination : 144-145

ISSN : 0039-2944

\section{Référence électronique}

Sébastien Baudoin, « PHILIPPE BERTHIER, Chateaubriand chemin faisant », Studi Francesi [En ligne], 184 (LXII I I) | 2018, mis en ligne le 03 juillet 2018, consulté le 15 novembre 2021. URL : http://

journals.openedition.org/studifrancesi/11826; DOI : https://doi.org/10.4000/studifrancesi.11826

Ce document a été généré automatiquement le 15 novembre 2021.

\section{(c) $(1) \odot$}

Studi Francesi è distribuita con Licenza Creative Commons Attribuzione - Non commerciale - Non opere derivate 4.0 Internazionale. 


\title{
PHILIPPE BERTHIER, Chateaubriand chemin faisant
}

\author{
Sébastien Baudoin
}

\section{RÉFÉRENCE}

PHILIPPE BERTHIER, Chateaubriand chemin faisant, Paris, Classiques Garnier, 2017, 256 pp.

1 Alors que se profile, dans moins d'un an, l'événement marquant des 250 ans de la naissance de Chateaubriand, qui sera l'occasion de nombreux colloques organisés entre autres par la Société Chateaubriand (outre le grand colloque des 5 et 6 juin 2018 intitulé «Nouvelles Perspectives critiques» qui se déroulera à Paris, les 13 et 14 septembre 2018 à Saint-Malo aura lieu le colloque «Chateaubriand et la Bretagne» et, en octobre 2018, à Rome, le colloque «Chateaubriand, Rome et l'Europe»), Philippe Berthier, éminent chateaubriandiste, stendhalien et aurévillien offre à Garnier et à ses lecteurs le plaisir de redécouvrir ses articles les plus saillants sur le chevalier de Combourg et son œuvre. Ne boudons pas notre plaisir: il s'agit là d'une fête des mots et des formules, comme il est d'usage sous la plume de Philippe Berthier, qui ne nous déçoit jamais.

Avant d'entrer dans ce domaine qui n'est pas infernal pour autant, un panneau nous indique immédiatement: lecteur, vous trouverez là un florilège bien libre, «une promenade critique» où vous pourrez butiner les fleurs de rhétorique du critique émérite qui a recomposé pour vous un «bariolage» (p. 11), une «arabesque» (p. 11), avec force excursus et sorties de routes volontairement incontrôlées.

Qu'en conclure? Que pour un volume qui s'annonce sans souci de structure, la composition n'en est pas moins recherchée et habile, si bien que l'on vient à se demander s'il ne s'agit pas, en préambule, d'un tour de passe-passe coutumier de Philippe Berthier, consistant à nous annoncer un désordre frivole alors que la structure du volume est bien établie (partie I sur le voyage, partie II sur les Mémoires et le temps, partie III sur les Muses, à savoir l'écriture et l'inspiration, partie IV sur deux rencontres éphémères, deux rêves enchantés, entre l'ange et la Muse, Sand et Mme Récamier). Il 
s'agit bien davantage pour l'auteur de ce beau florilège, quintessence d'un long voyage dans les contrées chateaubrianesque, de nous inviter à partager un gai savoir - dans tous les sens du terme - tant la joie y pointe, avec l'humour, à presque chaque ligne.

4 Nous gloserions ad libitum sur la plume virtuose bien connue de l'auteur s'il ne fallait pas aussi rendre compte du contenu. Que lit-on entre les saillies rhétoriques, les jeux de mots et le festival d'érudition qui nous éblouit de paragraphes en paragraphes? Nonpoint tant des jugements et des analyses définitives que des points d'ancrage de la rêverie critique, des sollicitations de l'imaginaire. Dans la lignée de Jean-Pierre Richard, Philippe Berthier nous donne à songer plus qu'il ne nous imprime dans l'esprit une certitude interprétative gravée dans le marbre. Et l'on se plaît alors à gambader dans ce champ critique bariolé: dans «René et ses espaces», l'on apprend combien le rapport au paysage se trouve accru à l'aune de la dilatation du personnage, perdu dans un «no man's land» face à une «diastole sans rivages» (p. 17) et qu'il trouve son avenir dans le passé (p. 19), livré à la "pulvérulence hystérique» (p. 21). René ne renaît pas mais se perd dans «l'insignifiance d'un non-lieu», «l'ailleurs définitif de son rêve» (p. 26). La relecture originale d'un René en décalage appelle alors la méditation décalée sur le rapport incertain entre Chateaubriand et son serviteur dans les Mémoires d'outre-tombe, analysé dans le second article du volume, où Philippe Berthier met très bien au jour la manipulation qu'opère Chateaubriand dans l'usage du texte de Julien. Qu'il s'agisse de relever l'ivresse du nom saisi en voyage («Poétique du nom»), d'analyser le dernier Rancé italien comme un nouveau René («Rancé en Italie, la fin du voyage»), Philippe Berthier s'engage déjà tacitement, comme Chateaubriand, sur cette «route du temps» qui est le titre de la seconde partie de son opus.

5 «L'hyperthéâtralisation du vécu» (p. 72) en période révolutionnaire dans les Mémoires d'outre-tombe («Le genre humain en vacances»), l'homme «du Non définitif» (p. 79) qui s'obstine dans l'incarcération et la révolte («les prisons du poète») dessinent une silhouette d'un Chateaubriand marginal - underground, si l'on faisait du berthierisme -, sondé dans ses aspérités les plus étranges. Ainsi de son obsession des chambres où il trouve refuge au gré de ses pérégrinations, comme celle qui, alors bloqué à Waldmünchen, lui permet de gloser ad libitum et de faire d'un rien un tout («Voyage autour de ma chambre»). La Bohème des Mémoires ("Châteaux en Bohème»), l'Italie crépusculaire de Vérone ou de Venise décadente («Dernières Italiques»), l'ultime révérence aux rois dans «Les Adieux de Bustschirad», l'étude des glissements de la plume rêveuse du mémorialiste («Incidences»), cette autre incidence - diagonale de l'esprit - qu'est le rire et l'ironie («Mémoires pour rire»), enfin la posture de l'héritier revendiquée par Chateaubriand fossoyeur de son siècle entrevu dans le rétroviseur de sa mémoire («Hériter»), on se demande après ce parcours exhaustif ce que n’a pas étudié Philippe Berthier dans ses sauts et gambades critiques.

6 La fin de l'ouvrage vient encore compléter cet effeuillage bien fourni de l'œuvre de l'Enchanteur: au "carrefour des Muses» - titre de la troisième partie - l'on croise les lumières transfigurantes de l'ekphrasis («Ut pictura memoria»), où la plume-pinceau affleure sous les ors de la mémoire panoramique de l'auteur, tout comme l'envoûtement musical («Musiques») dévoile Chateaubriand orfèvre des sons d'oiseaux (à défaut des noms) comme des grandes orgues de l'église. Souci de composition, nous l'affirmions, contre l'avis amusé de Philippe Berthier, habile mystificateur de son lecteur: tout se termine par une double rencontre en guise d'au revoir: après la sirène de la mer Morte qui inaugure cette quatrième et dernière partie de l'ouvrage - George 
Sand - entre admiration (feinte?) et irrévérence froide («La rosée de la mer Morte»), vient la Muse plus certaine - Juliette Récamier - et la correspondance tendre et langoureuse qui tissa les liens indéfectibles que Chateaubriand noua avec elle («La tendresse et la gloire»).

7 Philippe Berthier a brièvement introduit et n'a pas conclu. Mais comment conclure ce florilège réussi et virtuose? Mieux vaut laisser le lecteur sur sa faim, brûlant de relire de nouveau ces textes et d'y trouver matière à songer, éternellement, sur les rivages oubliés du patriarche d'outre-tombe... 